\title{
Estrutura Exportadora do Agronegócio e Impactos Socioeconômicos para os Países do Cone Sul
}

\author{
Luciane Rubin $^{1}$ e Paulo Waquil ${ }^{2}$
}

Resumo: Este estudo tem por objetivo investigar o nível de produtividade implícita das exportações associado a cada produto do agronegócio e a sofisticação revelada das cestas de exportações dos produtos do agronegócio para os países do Cone Sul, bem como os efeitos multiplicadores sobre a geração de renda agrícola, produto e ocupação, ao longo do período de 1992 a 2009. Para o cálculo do índice de produtividade implícita e da sofisticação revelada das exportações utiliza-se o método desenvolvido por Hausmann, Rodrik e Hwang (2005), e para a estimação do efeito multiplicador da sofisticação da cesta de exportação para as variáveis socioeconômicas, a análise de regressão múltipla. Em posse dos resultados e das análises de investigação, é possível afirmar que os resultados obtidos confirmam a hipótese de que, quanto mais sofisticada a pauta de exportação dos produtos do agronegócio junto aos países do Cone Sul, maiores serão os efeitos de crescimento da renda e do efeito multiplicador (transbordamentos) sobre a economia dos países. Contudo, ceteris paribus, estimular as exportações em produtos do agronegócio associados implicitamente ao maior nível de renda, constitui-se em importante estratégia de crescimento acelerado com base nas exportações e de obtenção de maiores níveis de bem-estar para a região.

Palavras-chaves: produtividade implícita, sofisticação das exportações, agronegócio, Cone Sul.

Abstract: This study aims to investigate the level of implicit productivity associated with exports of each product of agribusiness and the sophistication revealed of exports baskets of agribusiness products to the Southern Cone countries and the multiplier effects on the generation of agricultural income, product and occupation, in the period from 19922009. To calculate the implied productivity index and the revealed sophistication, the method developed by Hausmann, Hwang and Rodrik (2005) was used, and to estimate the multiplier effect of the sophistication of the export basket to socioeconomic variables,

1 Economista da UFSM, mestre em Integração Latino-Americana e doutora em Agronegócios pela Universidade Federal do Rio Grande do Sul. E-mail: luciane.rubin@yahoo.com.br

2 Engenheiro agrônomo, mestre em Economia Rural (IEPE/UFRGS) e doutor em Economia Agrícola (University of Wisconsin). Professor da Universidade Federal do Rio Grande do Sul (UFRGS), Faculdade de Ciências Econômicas, Departamento de Ciências Econômicas. E-mail: waquil@ufrgs.br 
the analysis of multiple regression was used. It is possible to say that the results confirm the hypothesis of the more sophisticated exports of the products of agribusiness of Southern Cone countries, the greater the effects of income growth and the multiplier effect (spillovers) for the economies of countries. However, ceteris paribus, to export agribusiness products implicitly associated with the higher income level constitutes an important strategy for accelerated growth, based on exports, and for achieving higher levels of welfare in the region.

Key-words: implicit productivity, sophistication of exports, agribusiness, Southern Cone.

Classificação JEL: Q17.

\section{Introdução}

O desempenho econômico dos países do Cone Sul, mais precisamente a partir do final da década de 70 , tem se caracterizado pelo baixo crescimento da renda per capita e pela sua elevada volatilidade, afastando-se da convergência de renda em relação aos países mais desenvolvidos.

Abordagens teóricas e empíricas desenvolvimentistas evidenciam a incapacidade da subregião em transformar suas estruturas produtiva e exportadora para setores e produtos mais dinâmicos no mercado internacional e de maior sofisticação tecnológica adaptada às especificidades da região. A forte concentração da especialização em commodities limita as possibilidades de integração dos setores e, por conseguinte, o aproveitamento das potencialidades e a integração destas com outros setores, como a indústria e o beneficiamento de insumos e serviços correlatos. Logo, o cenário propício aos países do Cone Sul, apontado pelos pesquisadores como o maior potencial mundial para fornecimento de alimentos para o mundo, não tem garantido o desenvolvimento sustentável e duradouro da sub-região. Os benefícios de geração de renda da especialização produtiva e exportadora da sub-região podem ser muito inferiores aos desejados e podem limitarse às questões macroeconômicas de balanço de pagamentos.

Diversos autores do desenvolvimento, como Dani Rodrik (2005), Ha-Joon Chang (2002) Sanjaya Lall (2003), Gabriel Palma (2004) e outros, têm estudado aspectos da experiência mundial de crescimento econômico em países em desenvolvimento, a fim de extrair elementos que possam sustentar explicações para os diferentes desempenhos econômicos entre os países. De modo geral, o que existe em comum entre a opinião desses autores é a capacidade que alguns Estados têm em alterar suas estruturas produtiva e exportadora de acordo com as exigências do mercado internacional, observando suas potencialidades internas.

O tipo de produto que um país produz e exporta interfere no seu desempenho econômico, tanto no lado da demanda quanto no da oferta. Do lado da demanda, os manufaturados de alto e médio conteúdo tecnológico apresentam rápido aumento na participação do comércio mundial nas últimas quatro décadas e os produtos básicos tiveram queda na participação, interferindo no poder de compra dos países que têm base exportadora nestes últimos (PALMA, 2004). Por outro lado, existem produtos do agronegócio que se associam à capacidade interna de desencadear benefícios multiplicadores para o resto da economia, criando estímulo de conhecimento científico, inovação e capacidades para a geração de encadeamento horizontal e vertical entre bens, setores, empresas, atividades, salários e rendimentos, chamados de bens "sofisticados". Desvendar quais bens têm essa capacidade, dadas as limitações e potencialidades específicas de cada país, e se especializar nesses bens, implica descobrir caminhos mais curtos para a criação de 
um processo retroativo de crescimento estável e duradouro.

A palavra sofisticação da produção ou das exportações está na literatura expressa de várias formas; entretanto, percebe-se uma conotação comum entre elas, associada aos efeitos que ela é capaz de produzir internamente ou não. Palma (2004) e Lall (2004), por exemplo, associam-na, de modo geral, à evolução da especialização ao longo da escada tecnológica e de qualidade; Hausmann e Klinger (2008), à geração do nível de rendimento ou de produtividade interna, e Hausmann e Hidalgo (2010), à geração de acúmulo de capacidades internas. Esses conceitos apoiamse na abordagem de "encadeamento" entre os setores de Hirschman (1981), no "enraizamento produtivo" de K. Polanyi (WILKINSON, 2002) e nos efeitos multiplicadores de Kaldor (1956), derivado da dinâmica da produção de alguns bens em gerar efeitos internos de aumento de produtividade associados à aprendizagem, ganhos de economias externas e dos "spill-overs" tecnológicos.

Grande parte dos recursos naturais, tecnológicos e de capital dos países do Cone Sul é despendida nas exportações de produtos agropecuários não processados, com baixo valor agregado, com baixa inclusão da agroindustrialização da pequena produção ao setor externo, deixando de gerar demanda e renda em torno do produto produzido e influenciando de forma significativa a geração de potencialidades produtivas induzidas pelo comércio exterior. $\mathrm{O}$ agronegócio pode apresentar-se como importante "motor" de uma estratégia de crescimento liderada pelas exportações. Porém, o sucesso ou insucesso de economias especializadas na exportação de produtos agropecuários vão depender do tipo de produto e dos efeitos multiplicadores gerados por ele (NORTH, 1959).

Neste contexto, evidencia-se a necessidade de estudos que possam interferir na formulação de políticas, tanto públicas quanto privadas, para maior aproveitamento do potencial do agronegócio da sub-região e para a construção do desenvolvimento duradouro e sustentável. Para tanto, questiona-se: qual o grau da produtividade implícita associado a cada produto do agronegócio? Como tem evoluído a sofisticação das cestas de exportações dos produtos do agronegócio nos países do Cone Sul? Em que medida o grau de sofisticação da cesta de exportação dos produtos do agronegócio tem impactado o desempenho socioeconômico da sub-região?

O objetivo do presente artigo consiste em estudar a produtividade implícita associada à cada produto do agronegócio e à evolução da estrutura exportadora quanto ao nível de sofisticação das cestas de produtos do agronegócio, bem como o efeito multiplicador dessa estrutura para a geração de renda agrícola, produto e ocupação junto aos países do Cone Sul, ao longo do período de 1992 a 2009.

\section{Crescimento e estrutura exportadora}

Vários são os modelos e abordagens econômicas que tentam explicar por que alguns países crescem mais que outros e conseguem atingir níveis maiores de desenvolvimento e de bem-estar social. Desde o século XV, acreditava-se que a principal forma de um país incrementar sua riqueza (acúmulo de ouro e prata) seria por meio do superávit comercial. Quatro séculos depois, nasceu a teoria das vantagens comparativas, que afirmava ser o livre-comércio um poderoso mecanismo para estimular a produção e o consumo, fonte de riqueza de uma nação e de bem-estar, e que os benefícios da especialização no comércio internacional (em capital ou em trabalho) viriam de forma recíproca para ambos os países participantes deste comércio. Em meados do século $X X$, surge a abordagem da economia do desenvolvimento a fim de contestar o monoeconomismo (uma só ciência econômica válida em qualquer tempo e lugar) e a reciprocidade das vantagens comparativas. 


\subsection{A estrutura exportadora e a economia do desenvolvimento}

A economia do desenvolvimento acreditava que era possível articular vantagens recíprocas entre dois grupos de países de modo que as relações seriam benéficas aos países que participariam. Entretanto, opunha-se à ideia de que os mecanismos de mercado seriam suficientes para fazer com que o desenvolvimento econômico fluísse das regiões mais adiantadas para as menos adiantadas. (HIRSCHMAN, 1981).

Os economistas do desenvolvimento, inspirados por Keynes, acreditavam que o sistema se move, constantemente, na mesma direção da mudança original, ao desequilíbrio, a menos que existam forças exógenas e planejadas no sentido de atuar em direção de posterior mudança (MYRDAL, 1968).

As críticas das modernas abordagens do desenvolvimento e subdesenvolvimento à economia ortodoxa, com relação ao papel do comércio internacional como equalizador das assimetrias entre os países, encontravam respaldo junto aos economistas keynesianos e cepalinos. Tais abordagens derivam de duas teses principais: a do comércio como motor do desenvolvimento, de Ragnar Nurkse, em 1950; e a tese estruturalista da deterioração secular dos termos de troca, formulada de forma simultânea e independentemente por Raul Prebisch, em 1949, e por Hans W. Singer, em 1959 (HIRSCHMAN, 1981; GONÇALVES et al., 1998).

Nurkse (1957) acreditava que as nações mais pobres, com a organização de sua economia em torno da exportação de matérias-primas, teriam dificuldades de participar de um mercado externo dinâmico e, assim, continuariam pobres devido ao "círculo vicioso" do subdesenvolvimento e da pobreza (mercados pequenos caracterizam-se por baixo nível de produtividade, e este, por sua vez, deriva da pequena quantidade de capital na produção, decorrente de o mercado ser pequeno). Neste caso, dada a incapacidade de formação de capital, o fosso entre países pobres e ricos só aumentaria.
Myrdal, dentro do mesmo espírito de Nurkse, do "circulo vicioso da pobreza", explica a constelação circular de forças que mantêm ou agravam a assimetria internacional entre os países, com bases históricas e estruturais internas e externas das economias. Os países subdesenvolvidos que tinham renda baixa e elevado desemprego de recursos acabavam mantendo a baixa qualidade dos fatores de produção e a baixa eficiência de seus esforços produtivos. Este processo cumulativo multicausal, chamado de "causação circular cumulativa", quando não controlado, promovia a desigualdade crescente ou "efeitos regressivos".

A outra influência na abordagem da economia do desenvolvimento e subdesenvolvimento é a tese de Prebisch e Singer. Desenvolvidas de forma independente, baseavam-se na hipótese de que haveria no comércio internacional uma tendência estrutural no tempo para a deterioração dos termos de troca entre bens primários, exportados pelos países periféricos ou subdesenvolvidos, e bens manufaturados, exportados pelos países centrais ou desenvolvidos (GONÇALVES et al., 1998; RODRÍGUEZ, 1981). Além disso, aceitando a hipótese de diferença relativa na produtividade dos bens agrícolas e manufaturados e de a produtividade ser mais elevada no centro, a deterioração na relação entre os preços traz consigo uma disparidade na evolução das rendas por unidade de trabalho, favorável ao centro (RODRÍGUEZ, 1981).

Somado à desvantagem nos termos de troca, para os cepalinos existia outro fenômeno, o aumento mais que proporcional da demanda de produtos industrializados em relação aos produtos primários (a visão cepalina admitia a Lei de Engel, de que a elasticidade-renda da demanda é maior para os produtos manufaturados do que para commodities). Existem algumas teorias que tentam explicar por que países que têm uma estrutura pouco sofisticada, concentrada em poucos produtos de baixa transformação e de baixo valor agregado, tendem a ter baixa produtividade, baixos salários e uma estrutura 
produtiva heterogênea (não complementar) e pouco diversificada.

\subsection{A "brecha tecnológica"}

Octavio Rodríguez (2002), técnico da Cepal, tenta reconstituir as ideias-chaves do estruturalismo e articular atualizações à abordagem diante de um novo contexto econômico mundial. Segundo o autor, o modo como o processo de globalização foi articulado, de abertura extrema e com a ausência de políticas tecnológico-produtivas, e a forma como se difunde o avanço do progresso técnico entre as economias centrais e periféricas, na atualidade, tem se configurado em diferenças estruturais crescentes, criando uma "brecha tecnológica".

A "brecha tecnológica" se amplia de forma sistêmica entre o centro e a periferia pela falta de complementaridade existente nesta última, afetando a especialização produtiva e a competitividade dos exportáveis em termos mundiais, que, associadas às deficiências na produção de novos bens, tendem a gerar desequilíbrios persistentes na balança comercial. $\mathrm{O}$ maior aumento da demanda por bens "tecnicamente mais complexos" em relação aos bens "tecnicamente simples" (explicado pela diferença na elasticidade-renda de exportação e importação desses bens) tende a ampliar as assimetrias em termos de crescimento da renda entre centro e periferia.

2.3. A "armadilha da estagnação" e o "acúmulo de capacidades"

Mais recentemente, são destaques alguns trabalhos como, por exemplo, os de Hausmann; Rodrik; Hwang (2005); Hausmann; Klinger (2008) e Hidalgo et al. (2007), que investigam a associação entre a mudança na estrutura produtiva $e$ exportadora e a taxa de crescimento mais elevada de alguns países. De modo geral, o tipo de produto que compõe a pauta e a sua diversificação está associado ao nível de renda dos países. Alguns países conseguem descobrir quais produtos estão associados ao nível de rendimento superior aos seus próprios e, assim, tendem a convergir para níveis de rendimentos mais elevados, implícitos nos avanços de sofisticação em suas pautas de exportações (de maior produtividade ou maior rendimento). Em outras palavras, os países se tornam o que exportam. Por outro lado, os países especializados em cesta de exportações de relativa sofisticação enfrentam um atraso no desempenho econômico. Portanto, não é somente a quantidade, mas também o tipo de produto exportado que importa para o crescimento mais acelerado dos países (HAUSMANN e KLINGER, 2008).

Mas como um país exportador de poucos produtos e de menor sofisticação passa para uma estrutura produtiva e exportadora de maior produtividade e maior grau de sofisticação? A resposta pode estar na perseguição de maior enraizamento interno da atividade produtiva em torno dos custos e capacidades já desenvolvidas. Dentro de um espectro de capacidades já desenvolvidas e de um nível de restrições e preferências dos países, algumas mercadorias comercializadas estão associadas a um nível mais elevado de produtividade do que outras (melhores salários, maior valor agregado às exportações e maior markup) e, também, em uma perspectiva dinâmica, associam-se à capacidade de gerar maior efeito de encadeamento interno para outros setores e atividades correlacionadas.

À medida que as economias vão se desenvolvendo, existe uma tendência à aglomeração de produtos na teia produtiva (espaço produto) em direção à fronteira de conhecimento, intensificando o acúmulo de recursos que são facilmente mobilizados para uma grande variedade de outras mercadorias, aumentando a diversificação e o grau de sofisticação das exportações. Os países em desenvolvimento, de modo geral, têm estruturas com baixo valor estratégico para a transformação estrutural (baixo efeito de encadeamento para outros setores e atividades) por estarem posicionados de forma afastada dos aglomerados produtivos (baixa complementaridade ao longo da cadeia produtiva).

A questão, porém, está em saber por que a maioria dos produtos mais sofisticados, geradores demaiorexternalidadeinterna positiva para oresto 
da economia, são, de maneira geral, produzidos e exportados por países de mais alta renda, enquanto os produtos menos sofisticados, menos conectados e que ocupam espaço na periferia do espaço produto (menor relação intersetorial), com baixo poder multiplicador, são produzidos por países de renda mais baixa. Há também, na literatura mais recente, uma abordagem que explora esta relação. As explicações estão nos microfundamentos da estrutura produtiva dos países em desenvolvimento.

Conforme Hausmann e Hidalgo (2010), o padrão de especialização dos países está relacionado à complexidade dos produtos e é medido pelo número e a natureza dos recursos específicos, não comercializáveis, que cada produto requer para a sua produção, chamado de capacidades. Se, para produzir e exportar um determinado produto, isso requer a apreensão de todos os recursos específicos a ele, então, existem produtos complexos, que requerem maior número de recursos do que outros e que são exportados apenas por poucos países. Logo, o número e a natureza específica dos recursos de cada país o diferenciam quanto à capacidade de produzir e exportar.

Os autores também afirmam que o retorno ao acúmulo de novos recursos aumenta exponencialmente com o número de recursos já disponível em um determinado país e, ao mesmo tempo, esse aumento da descoberta desses novos recursos aumenta também, de forma muito rápida, a complexidade média mundial para a produção de produtos. Isto é, o acúmulo de capacidades vai tornando a produção e a exportação de determinado produto cada vez mais sofisticada quanto à necessidade de capacidades específicas para produzi-lo. Para tanto, países com baixo poder de acumular capacidades tendem a ter baixo retorno para a descoberta de novos recursos, situação chamada pelos autores de "armadilha de estagnação" econômica. Já países com muitos recursos tendem a experimentar grandes retornos para o acúmulo e a diversificação de recursos adicionais.
A tendência a ganhos ou retornos elevados na especialização e ao acúmulo e diversificação de recursosadicionais às capacidades já existentes nos países de maior desenvolvimento está associada ao maior número de recursos já existentes e à capacidade implícita de complementaridade nos requisitos de capacidade.

Portanto, a "armadilha de estagnação" econômica pode ser aprofundada de forma espontânea, impulsionando as divergências de crescimento para as diferentes regiões do mundo e não para a convergência. A "armadilha" aprofunda-se mediante dois ângulos: um deles refere-se à complexidade na produção de determinado produto, pois, quanto maiores as exigências para produzi-lo, maiores são as dificuldades para aqueles países de capacidade relativa baixa; e o outro refere-se à dinâmica das capacidades, uma vez que existe a tendência de que o número total de capacidades no mundo torne-se relativamente cada vez mais acentuado. Ainda existe outra desvantagem para os países que têm uma pauta de exportação pouco diversificada e que requer capacidades adquiridas menos complexas: os produtos exportados por esses países, de modo geral, são produzidos e exportados por quase todos os países, por isso, sofrem maior concorrência. Já os países com a pauta bem diversificada, porque têm capacidades adquiridas complexas, exportam produtos em que poucos países se especializam.

Desta forma, países com limitações de capacidades devem adotar estratégias políticas de coordenação de recursos. Essas estratégias de coordenação de recursos devem observar o número e a natureza das capacidades presentes em cada país e o número de capacidades que podem ser compartilhadas, ou não, para a produção do novo bem. Isso implica dizer que as estratégias de crescimento lideradas pelas exportações em países em desenvolvimento, que, na maioria das vezes, apresentam limitação para sofisticar e diversificar suas estruturas exportadoras, devem ser direcionadas à produção de produtos próximos ao aglomerado do espaço 
produto existente, pois exigem um conjunto similar de capacidades.

Entretanto, para que as políticas de estratégia de crescimento que visam à transformação da estrutura produtiva e exportadora dos países sejam operacionalizadas, é preciso um considerável conhecimento dessas estruturas, das especificidades locais, de um amplo entendimento das diversas configurações das estruturas e das suas restrições de ligações. Contudo, diante das limitações administrativas e políticas dos governos, as políticas devem ser implementadas segundo um senso de prioridades (HAUSMANN, RODRIK e VELASCO, 2005).

\section{Procedimentos metodológicos}

A técnica estatística para a realização do primeiro objetivo compreende, em um primeiro momento, o cálculo do índice de produtividade implícita das exportações dos produtos do agronegócio e, num segundo momento, o cálculo do índice de sofisticação revelada dos produtos do agronegócio para a cesta de exportação dos países da região. Para o segundo objetivo, que é a estimação do efeito multiplicador para algumas variáveis socioeconômicas, é utilizada a análise de regressão múltipla.

Com relação à produtividade implícita dos produtos do agronegócio, estes têm por base os índices construídos por Hausmann, Rodrik e Hwang (2005). A novidade trazida pelos autores é a construção de um índice quantitativo que classifica as mercadorias negociadas em termos de produtividade implícita e, a partir daí, é possível calcular o grau de sofisticação das cestas de exportação dos países. Os autores perceberam que algumas mercadorias comercializadas estão associadas a maiores níveis de retorno do que outras e que os países que se especializam nesses produtos terão maior desempenho econômico.

A medida de produtividade para cada produto exportado é calculada pela seguinte fórmula:

$$
\operatorname{PRODY}_{k}=\sum_{j} \frac{\left(x_{j k} / X_{j}\right)}{\sum_{j}\left(x_{j k} / X_{j}\right)} Y_{j}
$$

em que:

$\mathrm{x}_{\mathrm{j} \mathrm{k}}=$ exportações do bem $\mathrm{k}$, do país j;

$X_{j}=$ total das exportações do país $\mathrm{j}\left(\mathrm{X}_{\mathrm{j}}=\sum_{\mathrm{j}} \mathrm{X}_{\mathrm{jk}}\right)$;

$Y_{j}=$ PIB per capita do país $j$;

Em seguida, os autores constroem uma medida que reflete o nível de rendimento ou produtividade da pauta de exportação (ou cesta de exportação) para cada país, chamado de índice ou grau de sofisticação revelada das exportações $\left(E X P Y_{i}\right)$. Este índice é calculado através da média ponderada da exportação do bem ou produto de um país, pelo índice de produtividade implícita PRODY $_{k}$. Os pesos são as exportações de bens (ou cesto) exportados por aquele país. O cálculo é dado por:

$$
\operatorname{EXPY}_{i}=\sum_{1}\left(\frac{X_{i 1}}{X_{i}}\right) \text { PRODY }
$$

em que:

$\mathrm{x}_{\mathrm{il}}=$ exportações do bem $\mathrm{l}$, do país i;

$\mathrm{X}_{\mathrm{i}}=$ total das exportações do país $\mathrm{i}$;

$\mathrm{PRODY}_{1}=$ índice de produtividade implícita do bem 1 , exportado pelo país i;

O índice de sofisticação revelada da cesta de exportação (EXPY) é uma medida do nível de rendimento ou produtividade associado ao padrão de especialização de um país e permite capturar a dinâmica da estrutura exportadora de cada país, quando medida ao longo do tempo. Porém, os autores evidenciam que a medida de sofisticação de uma cesta de produtos de exportação é inferida a partir da análise comparativa entre países, mas não é uma medida direta que possa indicar quanto essa cesta de exportação é boa ou não.

Neste trabalho, o objetivo é calcular a produtividade implícita média de 2007 a 2009, para 562 produtos do agronegócio, com base em 166 países e, ainda, o índice de sofisticação revelada das exportações dos produtos do agronegócio dos cinco países do Cone Sul, para o período de 1992 a 2009. Entretanto, para fins de comparação, o 
cálculo de sofisticação revelada foi realizado para todos os países que notificaram suas exportações e o PIB per capita junto ao banco de dados das Nações Unidas e da Unctad.

Segundo Triviños (1987), nas ciências sociais, cabe ao pesquisador construir conceitos, à luz dos traços da realidade que se observa, adaptadas ao meio, a fim de dar significado aos fenômenos que estuda. Para tanto, quando nos referimos a produtos do agronegócio, estamos considerando as rubricas das seguintes seções da Classificação Uniforme para o Comércio Internacional (CUCI), revisão 2, desagregado a cinco dígitos, relacionados na Tabela 1.

Com relação à execução do segundo objetivo, a estimação do efeito multiplicador da estrutura agroexportadora dos países, mais precisamente na estimação do efeito socioeconômico para os países em relação à renda agrícola (valor adicionado agrícola), no produto (PIB constante, em valores de 2005) e geração de ocupação (taxa de emprego sobre a população total) para os países, no período de 1992-2009, será utilizada a análise de regressão.
O modelo empregado para a análise é do tipo regressão múltipla, com dados temporais, que tem por base a seguinte função:

$\log (Y i)=f\left[\left(\log \mathrm{EXPY}_{\mathrm{A}}\right),\left(\log \mathrm{EXPY}_{\mathrm{B}}\right),\left(\log \left(\mathrm{EXPY}_{\mathrm{C}}\right)\right]\right.$

sendo que $Y_{i}$ representa a variável a ser explicada (renda agrícola, produto e ocupação) e $\operatorname{EXPY}_{A \rightarrow C}$ são as medidas de sofisticação revelada das exportações classificadas por categorias. Com o intuito de evitar problemas de escala, as variáveis serão logaritmizadas.

As categorias de cestas de sofisticação revelada, depois de calculada a produtividade implícita para cada produto selecionado, são classificadas da seguinte forma: a primeira, a cesta de produtividade implícita baixa [EXPY(A)], é composta por produtos do agronegócio que alcançaram índices de produtividade implícita entre $252<$ PROY <5.999; a segunda cesta, a de produtividade implícita média [EXPY(B)], é formada pelos produtos de produtividade implícita que ficaram mais próximos da média, isto é, aqueles produtos de produtividade implícita

Tabela 1. Produtos do agronegócio selecionados

\begin{tabular}{|c|c|c|}
\hline Títulos das Seções e & Capítulos & Descrição \\
\hline $\begin{array}{l}\text { Seção } 0 \text { - Produtos alimentícios e ani- } \\
\text { mais vivos }\end{array}$ & $\begin{array}{l}00,01,02,03,04 \\
05,06,07,08 \text { e } 09\end{array}$ & Consideram-se todos os 178 produtos da seção. \\
\hline Seção 1 - Bebidas e Tabaco & 11 e 12 & Consideram-se todos os 13 produtos da seção. \\
\hline $\begin{array}{l}\text { Seção } 2 \text { - Materiais em bruto, não co- } \\
\text { mestíveis, exceto combustíveis }\end{array}$ & $\begin{array}{l}21,22,23,24,25 \\
26,29 \text { e o Grupo } \\
271\end{array}$ & 85 produtos dos capítulos, incluindo os fertilizantes do grupo 271. \\
\hline $\begin{array}{l}\text { Seção } 4 \text { - Óleo, gorduras e ceras de } \\
\text { origem animal e vegetal }\end{array}$ & 41,42 e 43 & Todos os 27 produtos da seção. \\
\hline $\begin{array}{l}\text { Seção } 5 \text { - Produtos químicos e rela- } \\
\text { cionados }\end{array}$ & $\begin{array}{l}51,53,54,55,56 \\
\text { e } 59\end{array}$ & $\begin{array}{l}56 \text { produtos dos capítulos, referentes aos álcoois e outros produtos } \\
\text { químicos orgânicos, os óleos e essências e preparações de limpeza, } \\
\text { os fertilizantes, herbicidas, fungicidas e pesticidas, os amidos, glú- } \\
\text { ten, proteínas etc. }\end{array}$ \\
\hline $\begin{array}{l}\text { Seção } 6 \text { - Produtos manufaturados, clas- } \\
\text { sificados segundo os materiais }\end{array}$ & $61,63,64$ e 65 & $\begin{array}{l}121 \text { produtos dos capítulos, relacionados às manufaturas de couro } \\
\text { e peles, borracha natural, madeira e cortiça, fios têxteis e conexos } \\
\text { de algodão, lã e seda. }\end{array}$ \\
\hline $\begin{array}{l}\text { Seção } 7 \text { - Máquinas e equipamentos de } \\
\text { transporte }\end{array}$ & 72 & $\begin{array}{l}44 \text { produtos do capítulo, que compreende as máquinas agrícolas, } \\
\text { tratores, maquinaria para trabalhar com couro, papel e elaborações } \\
\text { alimentícias. }\end{array}$ \\
\hline $\begin{array}{l}\text { Seção } 8 \text { - Artigos manufaturados diver- } \\
\text { sos }\end{array}$ & $82,83,84$ e 85 & $\begin{array}{l}38 \text { produtos dos capítulos, que se referem aos móveis de madeira, } \\
\text { bolsas, calçados e acessórios de couro e vestuário de algodão, lã e } \\
\text { seda. }\end{array}$ \\
\hline
\end{tabular}

Fonte: Seleção a partir da UNContrade (2011). 
Tabela 2. Variáveis utilizadas

\begin{tabular}{lccc}
\hline \multicolumn{1}{c}{ Variáveis } & Fonte & Unidade de Medida & Anos \\
\hline Exportação & UNComtrade & US\$ & $1992-2009$ \\
PIB per capita & UNCTADstat & US\$ constante (2005) & $1992-2009$ \\
Renda agrícola (Valor adicionado agrícola) & UNCTADstat & US\$ constante (2005) & $1992-2009$ \\
Produto (PIB constante) & UNCTADstat & US\$ constante (2005) & $1992-2009$ \\
Ocupação (Emprego/população) & CEPALstat & Porcentagem & $1992-2008$ \\
\hline
\end{tabular}

Fonte: Elaboração própria.

entre $6.000<\mathrm{PRODY}<15.999$; e a terceira cesta, ou de produtividade implícita elevada [EXPY(C)], compreende a cesta de produtos que atingiram os maiores valores de produtividade implícita, entre $16.000<$ PRODY < 63.313. Esta é apenas uma classificação para facilitar a análise deste trabalho, por isso não se trata de uma convenção universal.

Com o intuito de sistematizar as informações e apresentá-las de forma mais clara, relacionase, na Tabela 2 , as fontes utilizadas e as variáveis consideradas:

\section{Análise e discussão dos resultados}

\subsection{O nível de produtividade implícita dos produtos do agronegócio}

Após o cálculo do índice, algumas estatísticas descritivas são apresentadas na Tabela 3, sendo que, na primeira linha, estão as informações estatísticas da produtividade implícita incluindo todos os produtos do agronegócio previamente selecionados. Os resultados levam a constatar que os produtos do agronegócio variam muito em relação à produtividade implícita. Essa variação pode ser percebida por meio dos valores de produtividade implícita mínima e máxima, que apresentam distâncias elevadas entre si.

$\mathrm{O}$ de menor valor foi apresentado pelo produto "Peles de cabra e cabrito, em bruto", com PRODY de 252, exportados por países de baixa renda per capita. O pequeno valor é explicado pela reduzida importância relativa do produto no comércio mundial e por ser exportado por dois países com reduzido PIB per capita. Do total exportado, 81,58\% provêm de Burundi e 18,42\%, da Indonésia, com PIB per capita de US\$ 151,80 e US\$ 1.545,6, respectivamente, em 2009.

O valor máximo foi registrado para o produto "Papel gomado ou adesivo em tiras ou rolos", com PRODY de 63.313, cujas exportações são dominadas pelos países de alta renda per capita. Os dez maiores exportadores representam 76,8\% do total exportado e também registram as maiores rendas per capita dos países que notificaram suas exportações. Em ordem decrescente de valor exportado do produto estão os seguintes países: França, Luxemburgo, EUA, Alemanha, Itália, Espanha, Reino Unido, Polônia, Canadá e Bélgica.

Ainda com relação à Tabela 3, cabe mencionar que as diferentes rubricas da Classificação Uniforme para o Comércio Internacional (CUCI) não expressam atributos de qualidade e marca, e podem estar subestimando os resultados para a média da produtividade implícita. Um exemplo especial e bastante perceptível é o caso dos produtos daSeção 08 , que tem o menorvalor médio da produtividade implícita entre as Seções. Isto se deve ao fato de $32 \%$ das exportações mundiais dos produtos do agronegócio selecionados na Seção 08 serem exportados pela China, que, por sua vez, apresenta PIB per capita relativamente baixo (US\$ 2.679,25). Por outro lado, encontram-se, também, entre os dez maiores exportadores dos produtos da Seção 08, países com elevado PIB per capita, como Itália, Hong Kong, Alemanha, França, Bélgica e Espanha. Especialmente nesta seção, os produtos registrados apresentam diferenças acentuadas quanto à qualidade e valor agregado e escondem diferentes apropriações de atributos e capacidades. Por exemplo, ao avaliar o preço unitário, verifica-se que o produto "Bolsas 
Tabela 3. Estatística descritiva da produtividade implícita para os produtos do agronegócio

\begin{tabular}{|c|c|c|c|c|c|}
\hline & Média & $\begin{array}{l}\text { Desvio } \\
\text { padrão }\end{array}$ & Mínimo & Máximo & № Prod. \\
\hline PRODY & 11.909 & 8.377 & 252 & 63.313 & 562 \\
\hline $\begin{array}{l}\text { Seção } 0 \text { - Produtos aliment. } e \\
\text { animais vivos }\end{array}$ & 9.619 & 6.823 & $\begin{array}{l}10 \\
\text { (Resíduos de amendoim) } \\
\end{array}$ & $\begin{array}{l}43.480 \\
\text { (Bacalhau seco ou salgado) }\end{array}$ & 178 \\
\hline Seção 1-Bebidas e Tabaco & 10.408 & 4.728 & $\begin{array}{l}2.947 \\
\text { (Fumo) }\end{array}$ & $\begin{array}{l}17.813 \\
\text { (Whisky) }\end{array}$ & 13 \\
\hline $\begin{array}{l}\text { Seção 2- Produtos crus não co- } \\
\text { mestíveis }\end{array}$ & 9.756 & 8.120 & $\begin{array}{l}252 \\
\text { (Peles de cabra e cabrito) }\end{array}$ & $\begin{array}{l}38.240 \\
\text { (Pele de visón em bruto) }\end{array}$ & 85 \\
\hline $\begin{array}{l}\text { Seção 4-Azeites, graças, orig. } \\
\text { animal e vegetal }\end{array}$ & 10.625 & 8.934 & $\begin{array}{l}912 \\
\text { (Óleo de amendoim) }\end{array}$ & $\begin{array}{l}36.518 \\
\text { (Óleo de fígado de peixe) }\end{array}$ & 27 \\
\hline $\begin{array}{l}\text { Seção 5- Prod. químicos e produ- } \\
\text { tos conexos }\end{array}$ & 15.337 & 8.201 & $\begin{array}{l}1.491 \\
\text { (Fertiliz. fosfatados) }\end{array}$ & $\begin{array}{l}34.075 \\
\text { (Enzimas) } \\
\end{array}$ & 56 \\
\hline Seção 6- Artigos manufaturados & 12.364 & 8.910 & $\begin{array}{l}1.139 \\
\text { (Tecidos de juta ou de outras } \\
\text { fibras têxteis) }\end{array}$ & $\begin{array}{l}63.313 \\
\text { (Papel gomado ou adesivo em } \\
\text { tiras ou rolos) }\end{array}$ & 121 \\
\hline $\begin{array}{l}\text { Seção 7-Máquinas e equipamen- } \\
\text { tos }\end{array}$ & 23.036 & 5.564 & $\begin{array}{l}12.254 \\
\text { (Máquina de costura) }\end{array}$ & $\begin{array}{l}36.972 \\
\text { (Máq. e aparelhos para fab. de } \\
\text { pasta celulósica) }\end{array}$ & 44 \\
\hline $\begin{array}{l}\text { Seção 8-Artigos manufaturados } \\
\text { diversos }\end{array}$ & 8.585 & 4.017 & $\begin{array}{l}3.287 \\
\text { (Vest. masc. de algodão) }\end{array}$ & $\begin{array}{l}20.042 \\
\text { (Artigos de peles com pelos) }\end{array}$ & 38 \\
\hline
\end{tabular}

Fonte: Cálculos feitos a partir dos dados da ONU, UNContrade (2011) e da UNCTAD, UCTADstat (2011).

de mão" apresenta preço unitário médio para a França, a Itália e a Índia, de US\$ 91,39, US\$ 88,95 e US\$ 3,68 , respectivamente. ${ }^{3}$

Mesmo diante das limitações dos dados que podem subestimar os resultados, os valores obtidos refletem o esperado. Há indícios fortes de que as vantagens em se especializar em um ou outro produto do agronegócio vão além das vantagens estáticas, oriundas do maior valor agregado nas exportações, mas também estão associadas a uma maior produtividade implícita que, na sua construção, leva em consideração a renda dos países que a exportam. Logo, o tipo de produto exportado por um país faz toda a diferença na obtenção de efeito de transbordamento e no crescimento futuro da renda de um país.

Na Tabela 4, estão alguns exemplos de produtos do agronegócio e os respectivos índices de produtividade implícita. Esses exemplos evidenciam que mesmo um produto do agro-

3 A China é o maior exportador do produto, porém, as quantidades exportadas em 2009 não estão disponíveis. negócio pertencendo a uma mesma cadeia produtiva, ele varia acentuadamente em termos de produtividade implícita.

Nos primeiros quatro produtos relacionados na tabela, referentes aos capítulos de "Animais vivos e Carnes e preparações de carne", percebese afastamentos no valor de produtividade implícita de exportação para "Bovino vivo, de raça, para reprodução" e "Bovinos vivos exportados, não de raça", entre a "Carne bovina, com osso" e "sem osso", indicando que existem diferenças em termos de renda subsequente para os países que se especializam em um ou outro produto. Mas por que isso acontece, já que os produtos estão no mesmo Capítulo, isto é, não se distanciam em termos de avanços ao longo da cadeia produtiva? O que parece ser razoável pensar é que, entre os dois produtos de cada capítulo, existem diferenças significativas em termos de capacidades internas para a especialização no comércio mundial em um ou outro produto, isto é, conforme já discutido, o conceito de sofisticação das exportações vai além do conceito tradicional de avanços na "escada tecnológica", cujo objetivo é elevar 
o valor a partir do aumento do grau de elaboração primária para secundária, mas também implica subir na "escada de capacidades adquiridas".

Paísesquebuscama sofisticaçãodesua estrutura produtiva e exportadora, no caso de exportar animais de raça em vez daqueles que não são de raça, por exemplo, requerem o desenvolvimento de um complexo processo de capacidades adquiridas que vai desde a simples incorporação de práticas e processos qualificados de governança e de controle, de "espírito empreendedor", definido por Schumpeter, até o desenvolvimento de pesquisas na fronteira do conhecimento, como biotecnologia celular e reprodutiva. Essas capacidades geram efeitos de transbordamento positivo, através do desenvolvimento de conhecimentos para outros setores e produtos, como biomedicina e indústria farmacêutica, melhoramento genético dos rebanhos, diminuição da transmissão de enfermidades de suínos, aves, ovinos, e na formação e qualificação profissional e, consequentemente, níveis salariais mais elevados e rendas mais produtivas. Também a evolução na sofisticação da especialização internacional gera, de forma espontânea ou por imitação, novas demandas internas, sejam elas em escala primária, industrial ou de serviço.

Um estudo de Gonçalves (2008) mostra que a exportaçãode "Bovinovivo,não deraça" peloBrasil é uma atividade injustificável economicamente e deve ser substituída pela exportação de carne refrigerada ou congelada. "Bovino vivo, não de raça" é considerada uma commodity "inferior", associada a um baixo valor agregado, de baixo dinamismo no mercado internacional, baixa elasticidade-renda de demanda e elasticidadepreço desfavorável, gerando padrões de comércio exterior retrógrados. A exportação da commodity não traz efeito de transbordamento positivo para a economia doméstica brasileira e inibe as potencialidades de modernização do padrão de comércio exterior na cadeia produtiva da carne.

O mesmo raciocínio se aplica, por exemplo, para um país que se especializa na exportação de carne bovina com osso, cujo valor no mercado internacional é maior. O país necessita do reconhecimento de "região livre de doença ou praga dentro de um país" por parte dos países importadores, principalmente junto aos maiores mercados. A princípio, para garantir tal reconhecimento, além da erradicação de doenças epidemiológicas, é necessária a consolidação do processo de qualidade ao longo da cadeia produtiva que, por sua vez, requer práticas efetivas de gestão com base no código da Organização Internacional de Epizootias; informação e registros consistentes de todo o processo produtivo e de comercialização; requisitos e critérios de bem-estar animal e ambiental; padronização dos cortes etc. A incorporação efetiva dessas

Tabela 3. Índice de Produtividade Implícita, 2007-2009, a preços e taxa de câmbio de 2005

\begin{tabular}{cclc}
\hline \multirow{2}{*}{ Capítulo } & $\begin{array}{c}\text { CUCI } \\
\text { Rev.02 }\end{array}$ & \multicolumn{1}{c}{ Produto } & PRODY \\
\hline \multirow{2}{*}{00} & 00111 & Os animais da espécie bovina, vivo, de raça pura para a reprodução & $17.105,44$ \\
& 00119 & Os animais da espécie bovina, vivo, não de raça pura & $5.534,26$ \\
\hline 01 & 01111 & Carne bovina fresca, refrigerada ou congelada, com osso & $12.643,71$ \\
& 01112 & Carne bovina fresca, refrigerada ou congelada, desossada & $8.013,64$ \\
\hline 04 & 04601 & Farinha de trigo ou de centeio & $5.171,63$ \\
& 04841 & Pão, biscoito, bolachas & $14.076,60$ \\
& 0488 & Extratos de malte; prepar. de cereais com menos de 50\% de cacau & $19.253,95$ \\
\hline 07 & 07111 & Café não torrado, cascas de café e peles & $1.123,07$ \\
& 07112 & Café torrado & $18.469,31$ \\
& 0721 & Cacau, cru torrado & $1.272,29$ \\
& 0730 & Chocolate e outras preparações contendo cacau, n.e.s & $14.912,23$ \\
\hline
\end{tabular}

Fonte: Cálculos feitos a partir dos dados da ONU, UNContrade (2011) e da UNCTAD, UNCTADstat (2011). 
práticas pode desencadear demandas de maior profissionalização, de investimentos e de inovação, para um ambiente mais amplo da economia que não apenas no setor de exportação de carnes com osso.

De modo geral, tal raciocínio serve para um grande número de produtos do agronegócio. A sofisticação da estrutura produtiva pode implicar não apenas em avanços ao longo da "escada tecnológica", mas também esforços para a escalada de qualificação do produto, que envolve conceitos de sustentabilidade, capacidades desenvolvidas, pesquisa, uso de tecnologias inovadoras etc.

Entretanto, na relação do índice de produtividade implícita dos 20 produtos de maior valor exportado pelos países do Cone Sul, visualizados na Tabela 5, pode ser observado que, de modo geral, a região se especializa em produtos de baixa produtividade implícita. Dos 20 produtos do agronegócio de maior valor exportado, apenas sete deles têm índices de produtividade implícita acima da média. Ainda, os quatro primeiros de maior exportação, que representam $49 \%$ das exportações da região em produtos do agronegócio, têm índices muito abaixo da média.

Por sua natureza, os países grandes, como o Brasil, por exemplo, que têm nos produtos do agronegócio participação elevada na sua pauta de exportação, tendem a concentrar boa parte das exportações dos produtos de maior valor exportado junto à região. Por outro lado, também participam com elevado percentual em produtos doagronegócio com baixa produtividade implícita (soja, café, açúcar, carne bovina etc.). Entretanto, o Chile, por exemplo, que aparece com participação elevada nos três dos sete produtos de maior produtividade implícita, tem sido citado como o país latino-americano que vem perseguindo, de mais longa data, a agregação de valor às suas exportações de produtos do agronegócio.

Tabela 4. Índice de Produtividade Implícita para os 20 produtos de maior importância na América Latina e Caribe

\begin{tabular}{ccclc}
\hline & CUCI2 & Valor Exp. (2009) & \multicolumn{1}{c}{ Produto } & PRODY \\
\hline 1 & 2222 & 14.370 .270 .866 & Soja em grão & $4.135,61$ \\
2 & 08131 & 13.011 .327 .894 & Bagaço e outros resíduos da extração do óleo de soja & $4.577,71$ \\
3 & 0611 & 6.165 .172 .484 & Açúcares de beterraba e cana, em bruto, sólido & $4.010,52$ \\
4 & 01112 & 6.038 .435 .229 & Carne bovina fresca, refrigeradas ou congeladas, desossadas & $8.013,64$ \\
5 & 0114 & 5.418 .381 .771 & Carne de aves, frescas, refrigeradas ou congeladas & $13.512,11$ \\
6 & 25172 & 5.010 .850 .226 & Pasta de madeira, celulose, soda ou sulf., branq.ou semibranq. & $19.163,15$ \\
7 & 4232 & 4.699 .531 .459 & Óleo de soja & $4.523,91$ \\
8 & 07111 & 3.761 .606 .819 & Café, não torrado com ou sem casa & $1.123,07$ \\
9 & 0440 & 3.348 .847 .745 & Milho, não moído & $5.278,70$ \\
10 & 0612 & 2.549 .426 .283 & Açúcar refinado de cana, beterraba e etc. & $6.681,60$ \\
11 & 0149 & 2.273 .016 .985 & Preparações e conservas de carne ou outras miudezas & $12.580,42$ \\
12 & 11212 & 2.021 .626 .228 & Vinho de uvas frescas & $12.131,69$ \\
13 & 6114 & 2.001 .429 .913 & Couro de outro gado bovídeo (incl.búfalo) e equino & $7.899,96$ \\
14 & 0342 & 1.742 .340 .954 & Peixes congelados, exceto filetes & $6.533,76$ \\
15 & 05851 & 1.630 .762 .933 & Resinas naturais; derivados de borracha natural & $7.659,33$ \\
16 & 0412 & 1.487 .885 .258 & Arroz descascado, mas não preparado & $10.453,07$ \\
17 & 0113 & 1.453 .764 .687 & Carne de suíno fresca, refrigerada ou congelada \\
18 & 51216 & 1.380 .499 .016 & Álcool etílico, desnaturado & $30.572,14$ \\
19 & 05751 & 1.324 .194 .161 & Uvas frescas & $13.170,07$ \\
20 & 85102 & 1.019 .412 .693 & Calçados com sola exterior de couro natural, de borracha & $7.020,10$ \\
\hline
\end{tabular}

Fonte: Feito a partir dos dados do UNContrade (2011) e UNCTADstat (2011). 


\section{A sofisticação das cestas de exportação dos produtos do agronegócio}

Conforme Hausmann, Hwang e Rodrik (2005), Hausmann e Klinger (2006 e 2008a), Liapis (2011), Bragança, Lemos e Amaral (2008), os países convergem para um determinado nível de rendimento de acordo com a sofisticação revelada de sua pauta de exportação. Com base nas afirmações dos autores, fica fácil compreender por que alguns países que se especializam em produtos agroindustriais têm desempenhos tão distintos. O tipo de produto do agronegócio exportado e o grau de sofisticação de sua pauta de especialização importam para o desempenho econômico dos países. Exportar mais de um determinado produto pouco sofisticado, com baixo valor ou com baixa capacidade de estimular outras atividades, seja por estar posicionado no início da cadeia produtiva ou por possuir qualidade inferior, incapaz de incorporar inovações e acúmulo de capacidades, ou ainda, por ser um produto não dinâmico no mercado internacional (baixa elasticidade de demanda e de preço), não garante o desempenho desejado e interfere na capacidade de alavancar a convergência de renda para níveis mais elevados.

Nos cálculos efetuados, os melhores desempenhos em termos de sofisticação revelada da cesta de exportação dos produtos do agronegócio foram registrados, de modo geral, nas economias mais avançadas e com alta produtividade (Finlândia, Suécia, Dinamarca, Suíça).

Na Tabela 6, são mostradas algumas estatísticas básicas da sofisticação revelada para os países que notificaram suas exportações junto às Nações Unidas, no sistema CUCI, Rev.2, e PIB per capita, para os anos 1992 e 2008. Nas duas primeiras linhas, estão as estatísticas de todos os países; nas duas linhas seguintes estão os países latino-americanos e caribenhos, e nas duas últimas linhas da tabela, as estatísticas dos cinco países do Cone Sul. Os resultados indicam elevação nos valores médios ao longo do período, tanto em termos mundiais quanto para América Latina e Caribe e países do Cone Sul.

Entre os países do Cone Sul, a média da sofisticação revelada ficou abaixo da média mundial para os dois períodos. Os maiores valores de sofisticação revelada da cesta de exportação de produtos do agronegócio entre os países da subregião ficaram com o Chile, e o de menor cesta de sofisticação revelada ficou com o Paraguai, apesar de ter apresentado evolução entre os dois períodos.

Para entender por que aumentos das exportações podem não significar evolução da sofisticação revelada da cesta de exportação, é exposta a seguir uma tabela com a evolução das exportações per capita em dólar e a sofisticação revelada das exportações dos produtos do agronegócio (EXPY), ao longo do período de 1992 a 2009, para os países do Cone Sul. Também para captar quais produtos, se os de baixa, média ou elevada produtividade implícita, mais contribuíram para o índice de sofisticação revelada e para as mudanças na estrutura das cestas de exportação, é apresentado um gráfico com a sofisticação revelada dividida em três categorias de cestas com produtos do agronegócio, conforme especificação na metodologia.

Tabela 5. Estatística descritiva para a sofisticação revelada

\begin{tabular}{|c|c|c|c|c|c|c|}
\hline & Ano & Média & Desvio Padrão & Mínimo & Máximo & № Observ. \\
\hline \multirow{2}{*}{ Mundo } & 1992 & 9.386 & 4.069 & 1.459 & 22.014 & 105 \\
\hline & 2008 & 9.459 & 3.858 & 1.753 & 24.578 & 152 \\
\hline \multirow{2}{*}{ ALC } & 1992 & 7.536 & 1.936 & 4.645 & 12.174 & 28 \\
\hline & 2008 & 8.653 & 3.366 & 1.753 & 20.678 & 34 \\
\hline \multirow{2}{*}{ Cone Sul } & 1992 & 8.711 & 2.846 & 4.645 & 12.173 & 5 \\
\hline & 2008 & 8.777 & 2.670 & 5.449 & 12.689 & 5 \\
\hline
\end{tabular}

Fonte: Cálculos feitos a partir de dados da UNContrade (2011). 
Com relação à exportação per capita e à sofisticação revelada da cesta dos produtos do agronegócio para os países do Cone Sul, é possível perceber que existe uma distância elevada entre eles. Conforme Tabela 7, os maiores valores de exportação per capita ficaram com o Uruguai, e os menores, com o Brasil, apesar de o Uruguai não possuir a cesta mais sofisticada na sub-região e o Brasil não ter a cesta menos sofisticada. O que fica claro é que existe uma diferença estrutural quanto à especialização das exportações, pois alguns países se especializam em produtos de menor sofisticação revelada e outros, em maior sofisticação, e ainda, outros caminham para a mudança na sua estrutura em direção à dos países de maior renda e outros para os produtos exportados pelos países de menor renda.

A maior taxa de crescimento de exportação per capita do agronegócio ficou com o Brasil, em $7,82 \%$; porém, isso não tem se traduzido na evolução da sofisticação da cesta do agronegócio quando comparados o primeiro e o último ano. Assim como no Brasil, no Uruguai, apesar de ter havido avanços na variável exportação per capita do agronegócio, a sofisticação da cesta diminuiu, graças ao aumento da concentração em produtos de menor produtividade implícita, conforme veremos a seguir.

Por outro lado, os maiores valores para a sofisticação da cesta de exportação durante o período foram registrados junto ao Chile, significando que este último tem uma estrutura exportadora do agronegócio mais sofisticada que os demais países da sub-região. Talvez, como se verá a seguir, isso ocorra porque os aumentos na variável exportação per capita dos produtos do agronegócio chileno concentram-se em avanços na sua sofisticação da cesta por produtos de maior produtividade implícita e, em países como a Argentina, o Brasil e o Uruguai, os avanços em termos de exportação per capita do agronegócio estão mais associados aos produtos de menor produtividade implícita.

Em termos de transformação estrutural da cesta de produtos exportados do agronegócio, entre as de baixa, média e alta produtividade implícita, representadas na Figura 1, o destaque entre os países do Cone Sul foi o Chile. A composição de sua cesta de exportação do agronegócio supera os $93 \%$ em produtos com produtividade implícita entre média e alta. Além disso, quando analisada a evolução entre os três anos, o país se especializou cada vez mais em produtos da terceira cesta, isto é, há uma evolução da sofisticação revelada para a terceira cesta, a EXPY(C), em detrimento da segunda cesta, a $\operatorname{EXPY(B).~O~Chile~avança~na~produção~daqueles~}$ produtos do agronegócio associados a estágios de rendimento mais elevados e sua estrutura exportadora de produtos do agronegócio converge aos dos países mais adiantados. Esses resultados levam a supor a hipótese de que

Tabela 6. Evolução da exportação per capita do agronegócio e da sofisticação revelada: países do Cone Sul

\begin{tabular}{llcccccccccc}
\hline \multicolumn{2}{c}{ Cone Sul } & $\mathbf{1 9 9 2}$ & $\mathbf{1 9 9 4}$ & $\mathbf{1 9 9 6}$ & $\mathbf{1 9 9 8}$ & $\mathbf{2 0 0 0}$ & $\mathbf{2 0 0 2}$ & $\mathbf{2 0 0 4}$ & $\mathbf{2 0 0 6}$ & $\mathbf{2 0 0 8}$ & $\mathbf{2 0 0 9}$ \\
\hline \multirow{2}{*}{ Argentina } & exp. per capita & 253,74 & 290,69 & 418,71 & 425,41 & 359,51 & 354,79 & 492,60 & 600,29 & $1.005,96$ & 747,34 \\
& EXPY & 7.488 & 7.542 & 7.525 & 7.474 & 7.862 & 7.538 & 7.716 & 7.837 & 7.423 & 7.526 \\
\hline \multirow{2}{*}{ Brasil } & exp. per capita & 91,79 & 119,31 & 127,67 & 127,41 & 117,94 & 136,61 & 214,57 & 263,74 & 377,94 & 329,91 \\
& EXPY & 9.018 & 8.409 & 8.800 & 8.591 & 9.276 & 8.890 & 8.973 & 9.040 & 9.099 & 8.448 \\
\hline \multirow{2}{*}{ Chile } & exp. per capita & 294,98 & 329,57 & 416,89 & 397,56 & 454,03 & 461,43 & 663,13 & 812,63 & $1.067,22$ & 920,43 \\
& EXPY & 12.174 & 12.553 & 12.373 & 12.038 & 12.428 & 12.465 & 12.521 & 12.468 & 12.689 & 12.362 \\
\hline \multirow{2}{*}{ Paraguai } & exp. per capita & 137,73 & 161,11 & 196,67 & 186,20 & 152,02 & 158,55 & 250,23 & 278,27 & 672,85 & 462,19 \\
& EXPY & 4.645 & 5.283 & 4.762 & 5.193 & 5.411 & 5.416 & 5.275 & 6.108 & 5.449 & 5.924 \\
\hline \multirow{2}{*}{ Uruguai } & exp. per capita & 421,86 & 450,08 & 596,03 & 636,11 & 516,48 & 442,22 & 685,24 & 918,87 & $1.387,56$ & $1.294,75$ \\
& EXPY & 10.229 & 10.149 & 9.985 & 10.220 & 10.391 & 9.763 & 9.392 & 9.656 & 9.226 & 9.021 \\
\hline
\end{tabular}

Nota: As exportações per capita estão expressas em dólares.

Fonte: Dados e cálculos feitos a partir da UNCTAD, UNCTADstat (2011) e da ONU, UNContrade (2011). 
Figura 1. Sofisticação da cesta de exportação do agronegócio conforme o grau de produtividade implícita: países do Cone Sul

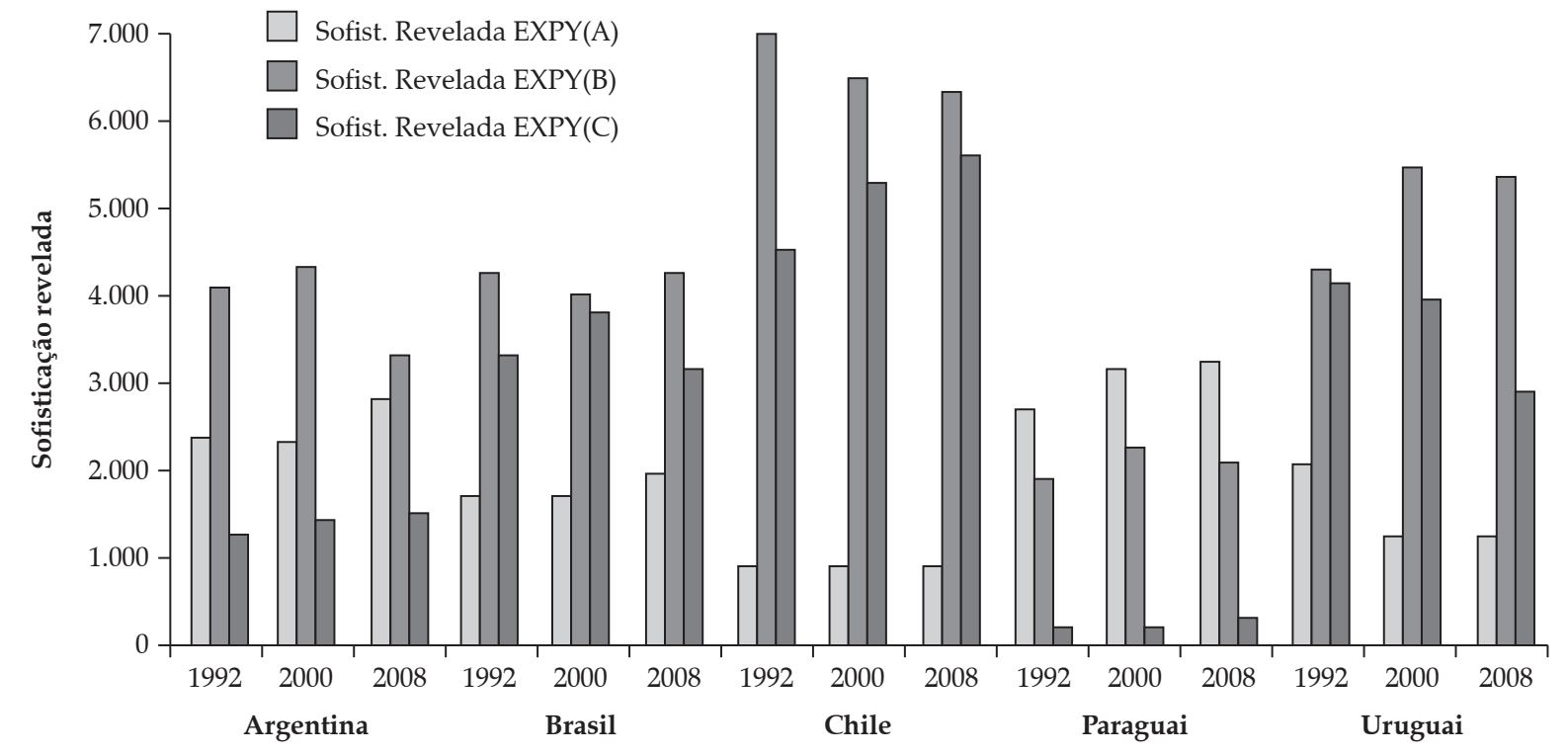

Fonte: Calculados com base na ONU, UNContrade (2011).

o agronegócio chileno deve contribuir para um crescimento subsequente mais robusto e consistente de sua renda per capita.

O inverso acontece com o Uruguai, pois, no início da série, o país tinha as cestas de média e alta sofisticação revelada com valores próximos, porém, a terceira cesta, as de produtos com produtividade implícita elevada, perde participação na sofisticação revelada, e a segunda cesta, a de produtos com produtividade implícita média, ganha participação. Entretanto, o país ainda mantém uma proporção elevada na sofisticação revelada em produtos de média e alta produtividade implícita, isto é, tem uma estrutura exportadora da cesta do agronegócio mais próxima à dos países de renda per capita mais elevada. É curioso notar que o Chile é um país com baixa capacidade de expansão no uso da terra entre os países da sub-região e, por esta razão, está cada vez mais voltado à diversificação e à especialização em produtos de maior produtividade implícita.

O Paraguai é o único país do Cone Sul em que a maior contribuição à sofisticação revelada da cesta de exportação do agronegócio é atribuída aos produtos da primeira categoria, os de produtividade implícita baixa. Isto quer dizer que o efeito de crescimento da renda com base nas exportações do agronegócio pode ser mais limitado que, por exemplo, o do Chile. Para a Argentina, observa-se um aumento da participação dos produtos de baixa produtividade implícita em detrimento dos de produtividade implícita média. Já para o Brasil, após ter apresentado, na primeira década, aumento da participação da produtividade implícita alta, na última década, observa-se queda na participação dos produtos de produtividade implícita alta, dada a maior participação dos produtos de produtividade implícita baixa. A elevação nos preços dos grãos no mercado internacional contribuiu para a maior especialização dos países do Cone Sul nesses produtos.

As análises até então quanto à produtividade implícita de cada produto e à evolução da sofisticação revelada de cada país, dão fortes indícios de que, em geral, o nível de renda dos países associa-se ao padrão de especialização de suas cestas de exportação dos produtos do agronegócio, isto é, quanto mais sofisticada a 
cesta de exportação dos produtos do agronegócio mais alto o nível de renda per capita e vice-versa. Neste próximo item, discutir-se-á a relação entre renda per capita, a sofisticação revelada da cesta de exportação do agronegócio e o impacto da estrutura exportadora em relação a algumas variáveis socioeconômicas.

\subsection{A sofisticação da estrutura exportadora e o impacto socioeconômico}

Nesta seção, o objetivoéinvestigar as seguintes questões: existe uma relação entre a sofisticação da cesta de exportação do agronegócio e a renda per capita posterior dos países? A sofisticação dessa cesta tem contribuído para o crescimento da renda, produto e emprego?

Nos dois gráficos a seguir, 2 e 3, visualiza-se a relação do nível de sofisticação revelada (EXPY) da cesta de exportação do agronegócio para os países do Cone Sul e seus respectivos PIBs per capita e, para fins de comparação, dos demais países latino-americanos e caribenhos. No primeiro gráfico, tem-se a correlação entre as duas variáveis em 1992 e, no segundo, para o ano de 2009.
Quanto a Figura 2, é possível observar que os países de renda mais elevada possuem cestas mais sofisticadas, ou seja, os países de maior renda per capita exportam produtos mais sofisticados. A correlação encontrada entre as variáveis, para o ano de 1992, foi de moderadamente forte, o que já era esperado, pois a relação reflete as características específicas de cada país e os seus respectivos graus de importância da cesta de produtos do agronegócio sobre a balança comercial. Por outro lado, existe um limitante, que é o número reduzido de observação, o que pode ter interferido no ajustamento dos eventos. Porém, conforme a Figura 3, o coeficiente encontrado para o ano de 2009 mostrou-se mais robusto, mesmo com o número limitado de variáveis.

$\mathrm{Na}$ Figura 2, são encontrados alguns pontos que se afastam da tendência de relação entre sofisticação revelada da cesta de exportação dos produtos do agronegócio com o respectivo PIB per capita. Em tese, estes pontos representam aqueles países que, ou possuem uma cesta mais sofisticada que sua renda (pontos acima da tendência) e, por isso, terão crescimento futuro mais elevado, ou possuem cestas menos sofisticadas (pontos

Figura 2. Relação entre PIB per capita e sofisticação revelada da cesta de exportação do agronegócio - 1992

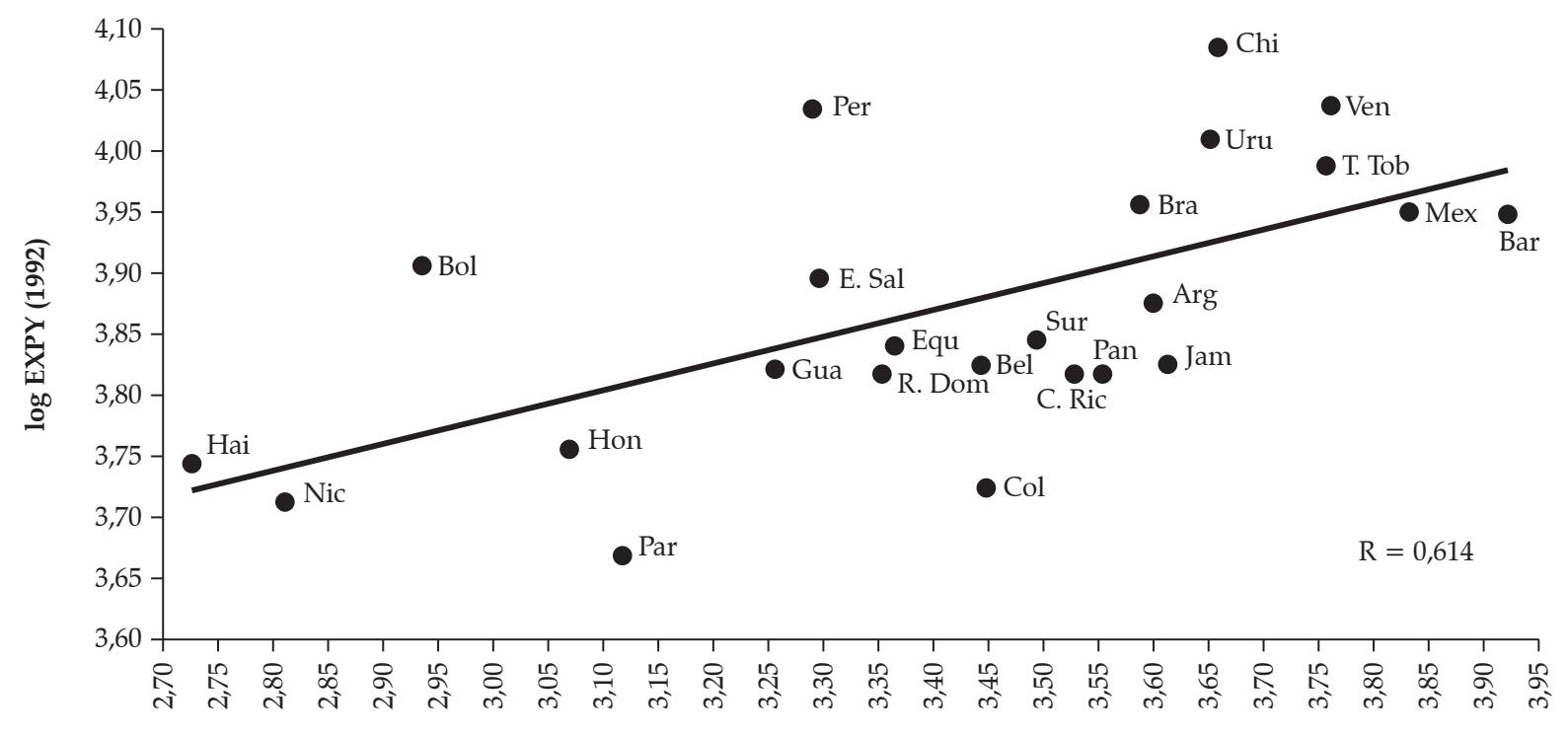

$\log$ PIB per capita (1992, a preços de 2005)

Fonte: Feito a partir dos dados da ONU, UNContrade (2011) e da UNCTAD, UNCTADstat (2011). 
abaixo da tendência) do que deveriam ter e, por conseguinte, a contribuição dessa cesta de exportação do agronegócio ao crescimento econômico será abaixo do seu potencial em relação aos países latino-americanos. Caso se tome como exemplo o Chile e o Peru, que têm cestas de exportação do agronegócio mais sofisticadas que o seu nível de renda para 1992, e se comparamos com o crescimento do PIB per capita, no período de 1992 a 2009, é possível perceber que os dois países da região, junto à República Dominicana e o Panamá, tiveram as maiores taxas de crescimento médio do PIB per capita no período, de 3,16\% e $3,51 \%$ ao ano (as taxas de crescimento médio da República Dominicana e do Panamá foram de $3,88 \%$ e 3,23\% ao ano, respectivamente).

Por outro lado, se olhamos para o Paraguai, que tem a menor sofisticação revelada para a cesta de exportação do agronegócio em 1992, entre os países latino-americanos e caribenhos que notificaram suas exportação junto ao UNContrade, percebe-se que ele está entre os que menos cresceram em termos de PIB per capita (taxa média de 0,05\% ao ano, entre 1992 e 2009), à frente apenas da Jamaica. O Paraguai, conforme discussão da Figura 1, possui quase a totalidade de suas exportações baseadas em produtos do agronegócio de baixa produtividade implícita. Neste caso, as exportações do país podem ter gerado um efeito reduzido de encadeamento setorial e de baixa capacidade de gerar externalidade tecnológica e de acúmulo de conhecimento, e, por conseguinte, o país tem sido incapaz de impulsionar o seu desenvolvimento econômico.

O fraco desempenho econômico da Jamaica, país de menor variação do PIB per capita no período $(0,002 \%)$, possui aumento da sofisticação revelada quase que exclusivamente impulsionada pelas reexportações de "Álcool etílico", importado do Brasil e reexportado para os EUA. Neste caso, apesar de o país ter apresentado evolução na sofisticação revelada, mudando a posição abaixo da tendência na Figura 2 para uma posição acima na tendência, na Figura 3, acredita-se que essas reexportações não foram capazes de gerar efeito de transbordamento para o resto da economia, já que toda a tecnologia e os investimentos em inovação, por exemplo, foram desenvolvidos em outro país, neste caso, no Brasil.

Figura 3. Relação entre PIB per capita e sofisticação revelada da cesta de exportação do agronegócio - 2009

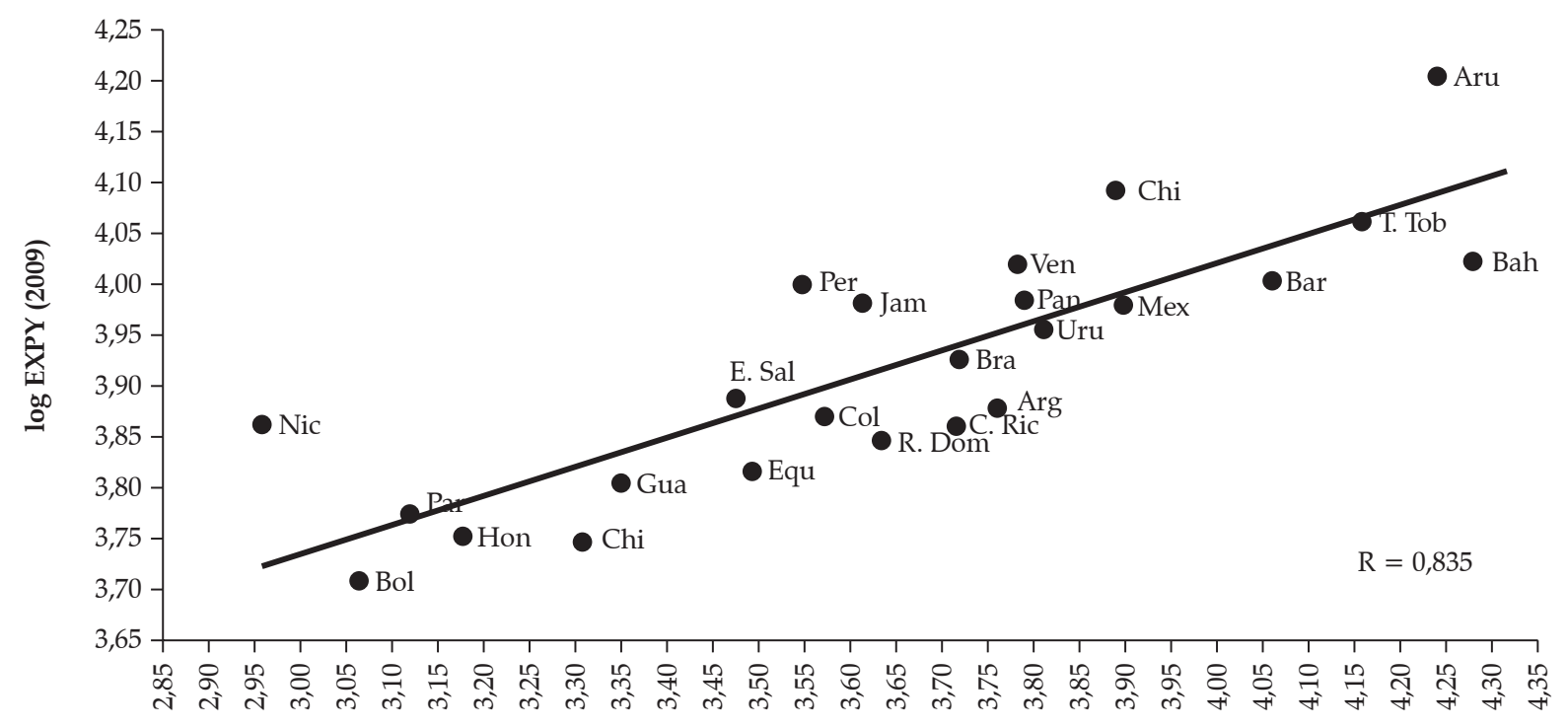

$\log$ PIB per capita (2009, a preços de 2005)

Fonte: Feito a partir dos dados da ONU, UNContrade (2011) e da UNCTAD, UNCTADstat (2011). 
Agora, com relação à correlação entre sofisticação e PIB per capita para 2009 (Figura 3), é possível verificar maior ajustamento entre os eventos, e o coeficiente de correlação está entre os limites de associação muito forte na relação entre as duas variáveis. Países como o Uruguai e o Brasil, que ficavam acima da linha de tendência da região em 1992, posicionaram-se levemente abaixo dessa linha, que agora é mais inclinada. A explicação pode estar associada, como já se apresentou anteriormente, à queda da participação dos produtos de maior produtividade implícita sobre a sofisticação revelada da cesta de exportação dos produtos do agronegócio. Essa queda na sofisticação pode representar problemas no desempenho econômico futuro dos países, principalmente no Uruguai, que apresenta forte dependência desses produtos na sua pauta de exportação.

Em Aruba, similar ao caso da Jamaica, o principal produto da sua cesta de exportação do agronegócio são as reexportações de "Whisky", que representaram, em 2009, cerca de 48,1\% das exportações totais, cuja produtividade implícita é elevada.

Agora, para analisar o efeito multiplicador da sofisticação da cesta de exportação do agronegócio, subdividida nas categorias de produtos com baixa produtividade implícita (EXPY(A)), média (EXPY(B)) e alta (EXPY(C), para os países do Cone Sul, foram utilizadas regressões a partir de séries históricas, de 1992 a 2009, para as variáveis renda agrícola e produto, e de 1992 a 2008, para a variável emprego. A diversidade nos resultados encontrados, conforme Tabelas 8 a 10, não permite chegar a uma conclusão única sobre os efeitos multiplicadores para os países, mas alguns casos merecem análise. O curto período de tempo é um limitador para a obtenção de resultados mais robustos, além disso, a década de 90 foi um período de forte instabilidade e de profundas transformações no sistema econômico, afetando os fundamentos econômicos dos países e interferindo na composição de tendências.

Tabela 7. Efeito multiplicador sobre a renda agrícola: Cone Sul

\begin{tabular}{|c|c|c|c|c|c|c|}
\hline \multicolumn{7}{|c|}{ Variável dependente: log Valor Adicionado Agrícola (em dólar constante e taxa de câmbio de 2005) } \\
\hline & $\begin{array}{c}\text { Variáveis } \\
\text { independentes }\end{array}$ & Coeficientes & Estatística t & $\mathbf{R}^{2}$ & $\begin{array}{c}\text { Nível de } \\
\text { significância }\end{array}$ & Observações \\
\hline \multirow{4}{*}{ Argentina } & Constante & $-0,479$ & $-0,089$ & \multirow{4}{*}{0,702} & \multirow{4}{*}{$5 \%$} & \multirow{4}{*}{18} \\
\hline & $\log \operatorname{EXPY}(\mathrm{A})$ & 1,774 & 2,360 & & & \\
\hline & $\log \mathrm{EXPY}(\mathrm{B})$ & 0,752 & 1,025 & & & \\
\hline & $\log \mathrm{EXPY}(\mathrm{C})$ & 0,620 & 2,712 & & & \\
\hline \multirow{4}{*}{ Brasil } & Constante & $-10,646$ & $-2,806$ & \multirow{4}{*}{0,776} & \multirow{4}{*}{$5 \%$} & \multirow{4}{*}{18} \\
\hline & $\log \mathrm{EXPY}(\mathrm{A})$ & 3,136 & 6,616 & & & \\
\hline & $\log \mathrm{EXPY}(\mathrm{B})$ & 2,025 & 4,325 & & & \\
\hline & $\log \mathrm{EXPY}(\mathrm{C})$ & 1,059 & 2,419 & & & \\
\hline \multirow{4}{*}{ Chile } & Constante & $-72,455$ & $-3,266$ & \multirow{4}{*}{0,746} & \multirow{4}{*}{$5 \%$} & \multirow{4}{*}{18} \\
\hline & $\log \mathrm{EXPY}(\mathrm{A})$ & 4,340 & 5,150 & & & \\
\hline & $\log \mathrm{EXPY}(\mathrm{B})$ & 12,730 & 3,331 & & & \\
\hline & $\log \operatorname{EXPY}(\mathrm{C})$ & 5,612 & 3,790 & & & \\
\hline \multirow{4}{*}{ Paraguai } & Constante & 2,402 & 1,428 & \multirow{4}{*}{0,784} & \multirow{4}{*}{$5 \%$} & \multirow{4}{*}{18} \\
\hline & $\log \mathrm{EXPY}(\mathrm{A})$ & 1,480 & 4,251 & & & \\
\hline & $\log \mathrm{EXPY}(\mathrm{B})$ & 0,157 & 0,618 & & & \\
\hline & $\log \mathrm{EXPY}(\mathrm{C})$ & 0,465 & 3,966 & & & \\
\hline \multirow{4}{*}{ Uruguai } & Constante & 13,715 & 4,836 & \multirow{4}{*}{0,630} & \multirow{4}{*}{$5 \%$} & \multirow{4}{*}{18} \\
\hline & $\log \mathrm{EXPY}(\mathrm{A})$ & $-0,319$ & $-1,234$ & & & \\
\hline & $\log \mathrm{EXPY}(\mathrm{B})$ & $-0,492$ & $-0,952$ & & & \\
\hline & $\log \mathrm{EXPY}(\mathrm{C})$ & $-0,495$ & $-3,260$ & & & \\
\hline
\end{tabular}

Fonte: Resultado da estimação. 
Tabela 8. Efeito multiplicador sobre o produto: Cone Sul

\begin{tabular}{|c|c|c|c|c|c|c|}
\hline \multicolumn{7}{|c|}{ Variável dependente: log PIB constante (em dólar e taxa de câmbio de 2005) } \\
\hline & $\begin{array}{c}\text { Variáveis } \\
\text { independentes }\end{array}$ & Coeficientes & Estatística $t$ & $\mathbf{R}^{2}$ & $\begin{array}{c}\text { Nível de } \\
\text { significância }\end{array}$ & Observações \\
\hline \multirow{4}{*}{ Argentina } & Constante & $-1,019$ & $-0,134$ & \multirow{4}{*}{0,578} & \multirow{4}{*}{$5 \%$} & \multirow{4}{*}{18} \\
\hline & $\log \mathrm{EXPY}(\mathrm{A})$ & 1,110 & 1,046 & & & \\
\hline & $\log \mathrm{EXPY}(\mathrm{B})$ & 0,074 & 0,071 & & & \\
\hline & $\log \operatorname{EXPY}(\mathrm{C})$ & 0,717 & 2,219 & & & \\
\hline \multirow{4}{*}{ Brasil } & Constante & $-7,421$ & $-2,261$ & \multirow{4}{*}{0,690} & \multirow{4}{*}{$5 \%$} & \multirow{4}{*}{18} \\
\hline & $\log \mathrm{EXPY}(\mathrm{A})$ & 2,121 & 5,173 & & & \\
\hline & $\log \mathrm{EXPY}(\mathrm{B})$ & 1,247 & 3,080 & & & \\
\hline & $\log \mathrm{EXPY}(\mathrm{C})$ & 0,548 & 1,448 & & & \\
\hline \multirow{4}{*}{ Chile } & Constante & $-65,068$ & $-2,708$ & \multirow{4}{*}{0,637} & \multirow{4}{*}{$5 \%$} & \multirow{4}{*}{18} \\
\hline & $\log \mathrm{EXPY}(\mathrm{A})$ & 3,719 & 4,075 & & & \\
\hline & $\log \mathrm{EXPY}(\mathrm{B})$ & 10,956 & 2,647 & & & \\
\hline & $\log \mathrm{EXPY}(\mathrm{C})$ & 4,695 & 2,928 & & & \\
\hline \multirow{4}{*}{ Paraguai } & Constante & 0,750 & 0,824 & \multirow{4}{*}{0,787} & \multirow{4}{*}{$5 \%$} & \multirow{4}{*}{18} \\
\hline & $\log \mathrm{EXPY}(\mathrm{A})$ & 0,673 & 3,572 & & & \\
\hline & $\log \mathrm{EXPY}(\mathrm{B})$ & 0,032 & 0,230 & & & \\
\hline & $\log \mathrm{EXPY}(\mathrm{C})$ & 0,282 & 4,442 & & & \\
\hline \multirow{4}{*}{ Uruguai } & Constante & 7,884 & 2,087 & \multirow{4}{*}{0,423} & \multirow{4}{*}{$5 \%$} & \multirow{4}{*}{18} \\
\hline & $\log \mathrm{EXPY}(\mathrm{A})$ & $-0,348$ & $-1,011$ & & & \\
\hline & $\log \mathrm{EXPY}(\mathrm{B})$ & $-0,377$ & $-0,548$ & & & \\
\hline & $\log \mathrm{EXPY}(\mathrm{C})$ & $-0,330$ & $-1,630$ & & & \\
\hline
\end{tabular}

Fonte: Resultado da estimação.

Tabela 9. Efeito multiplicador sobre o emprego: Cone Sul

\begin{tabular}{|c|c|c|c|c|c|c|}
\hline \multicolumn{7}{|c|}{ Variável dependente: Emprego sobre a População (porcentagem) } \\
\hline & $\begin{array}{c}\text { Variáveis } \\
\text { independentes }\end{array}$ & Coeficientes & Estatística t & $\mathbf{R}^{2}$ & $\begin{array}{c}\text { Nível de } \\
\text { significância }\end{array}$ & Observações \\
\hline \multirow{4}{*}{ Argentina } & Constante & $-237,3$ & $-0,751$ & \multirow{4}{*}{0,556} & \multirow{4}{*}{$5 \%$} & \multirow{4}{*}{17} \\
\hline & $\log \mathrm{EXPY}(\mathrm{A})$ & 58,3 & 1,323 & & & \\
\hline & $\log \mathrm{EXPY}(\mathrm{B})$ & 7,9 & 0,184 & & & \\
\hline & $\log \mathrm{EXPY}(\mathrm{C})$ & 20,3 & 1,487 & & & \\
\hline \multirow{4}{*}{ Brasil } & Constante & $-261,0$ & $-3,343$ & \multirow{4}{*}{0,654} & \multirow{4}{*}{$5 \%$} & \multirow{4}{*}{17} \\
\hline & $\log \mathrm{EXPY}(\mathrm{A})$ & 43,6 & 4,191 & & & \\
\hline & $\log \mathrm{EXPY}(\mathrm{B})$ & 37,7 & 3,780 & & & \\
\hline & $\log \mathrm{EXPY}(\mathrm{C})$ & 12,8 & 1,386 & & & \\
\hline \multirow{4}{*}{ Chile } & Constante & 799,7 & 1,771 & \multirow{4}{*}{0,271} & \multirow{4}{*}{$5 \%$} & \multirow{4}{*}{17} \\
\hline & $\log \mathrm{EXPY}(\mathrm{A})$ & $-38,1$ & $-2,108$ & & & \\
\hline & $\log \mathrm{EXPY}(\mathrm{B})$ & $-122,4$ & $-1,580$ & & & \\
\hline & $\log \mathrm{EXPY}(\mathrm{C})$ & $-46,0$ & $-1,535$ & & & \\
\hline \multirow{4}{*}{ Paraguai } & Constante & $-121,0$ & $-1,811$ & \multirow{4}{*}{0,718} & \multirow{4}{*}{$5 \%$} & \multirow{4}{*}{17} \\
\hline & $\log \mathrm{EXPY}(\mathrm{A})$ & 41,3 & 3,008 & & & \\
\hline & $\log \mathrm{EXPY}(\mathrm{B})$ & 1,4 & 0,138 & & & \\
\hline & $\log \mathrm{EXPY}(\mathrm{C})$ & 17,9 & 3,783 & & & \\
\hline \multirow{4}{*}{ Uruguai } & Constante & 78,8 & 1,660 & \multirow{4}{*}{0,697} & \multirow{4}{*}{$5 \%$} & \multirow{4}{*}{17} \\
\hline & $\log \mathrm{EXPY}(\mathrm{A})$ & $-0,1$ & $-0,030$ & & & \\
\hline & $\log \operatorname{EXPY}(\mathrm{B})$ & 2,6 & 0,303 & & & \\
\hline & $\log \mathrm{EXPY}(\mathrm{C})$ & $-9,4$ & $-3,219$ & & & \\
\hline
\end{tabular}

Fonte: Resultado da estimação. 
Os coeficientes de determinação foram, de modo geral, considerados relativamente elevados, já que a cesta de exportação do agronegócio não representa a totalidade das exportações e porque, teoricamente, muitas outras variáveis interferem no desempenho dos países. Também as respostas das variáveis regredidas à sofisticação revelada, nas três categorias de cestas, apresentaram resultados bem distintos para os países.

Entretanto, é possível afirmar que o efeito multiplicador da sofisticação revelada das cestas de exportações de produtos do agronegócio (Tabelas 8, 9 e 10) em relação às variáveis regredidas é positivo, exceto para o Uruguai. Entretanto, a maioria dos coeficientes das categorias de cesta de sofisticação para o Uruguai foi não significativa para o nível de confiança de $95 \%$, exceto a terceira cesta, a $\operatorname{EXPY}(C)$, que se mostrou significativa para as variáveis regredidas renda agrícola e emprego. Esta categoria de cesta apresentou, conforme item anterior, uma queda na participação da sofisticação das exportações do agronegócio.

O maior coeficiente de determinação para as variáveis renda agrícola, produto e emprego ficou com o Paraguai, sendo que apenas as categorias de cestas de produtividade implícita baixa e alta, EXPY (A) e (C), é que se mostraram significativas. Porém, como já era esperado, os maiores efeitos sobre as variáveis preditas ficaram com a primeira categoria de cesta de sofisticação, a EXPY (A). Apesar disso, o coeficiente desta cesta é bastante baixo quando se leva em consideração a proporção que ela representa às exportações totais do país. O baixo efeito multiplicador desta primeira categoria de cesta de sofisticação, dada a importância que representa, pode, em muito, estar associado ao reduzido efeito de encadeamento interno que a especialização em produtos de produtividade implícita baixa é capaz de produzir. Já o efeito mínimo sobre a renda agrícola da terceira categoria de cesta, que também se mostrou significativa ao nível de $5 \%$, pode ser explicado pela pequena parcela que os produtos de maior produtividade implícita representam sobre a cesta de sofisticação revelada.
Para o Brasil, que apresentou os segundos maiores coeficientes de determinação para as regressões, as categorias de cestas de produtos de baixa sofisticação e de média sofisticação foram, em ordem decrescente, as de maior significância e de maior efeito sobre renda agrícola, produto e emprego. Conforme discussão anterior, estas duas categorias de cestas foram as que mais avançaram na contribuição para a sofisticação revelada durante o período analisado. O Brasil é um grande exportador líquido de produtos do agronegócio, característica que contribui para o grau de associação entre o desempenho agrícola e as variáveis regredidas. Porém, segundo Ferranti et al. (2005), a alta concentração da terra e de capital e o baixo encadeamento a montante e a jusante da agricultura intensiva voltada à exportação no Brasil parecem mitigar o impacto da atividade agrícola sobre as variáveis socioeconômicas no País.

Com relação ao Chile, cujos resultados já eram esperados pelas análises anteriores, o país apresentou coeficiente significativo para as três categorias de cestas em relação às variáveis renda agrícola e produto, exceto para a variável emprego. A categoria de cesta do agronegócio que tem maior influência sobre a renda agrícola e o produto foi a segunda cesta, a de produtividade média. Apesar de esta cesta ter perdido contribuição junto à sofisticação revelada em favor da terceira categoria de cesta, a de maior produtividade implícita, ainda mantém um peso maior sobre as demais. Considerandose que os produtos do agronegócio representam a menor participação entre os países do Cone Sul, os resultados mostraram-se expressivos e vão ao encontro da teoria aqui evidenciada: países que se especializam em produtos mais sofisticados (com maior produtividade implícita) desfrutam de melhor desempenho nas variáveis socioeconômicas e, consequentemente, convergem para os níveis de renda dos países mais desenvolvidos. O bom resultado do Chile deve-se a uma variante de características de suas estruturas produtiva e exportadora do agronegócio, com grande peso sobre a descoberta 
e o desenvolvimento de capacidades, adaptadas às suas potencialidades e aptidões internas. $\mathrm{O}$ Chile é o país latino-americano que tem a maior integração entre a agricultura e os demais setores, logo, o impacto positivo sobre a economia é maior, conforme afirmação de Ferranti et al. (2005). Para Rodrik (2004), o Estado chileno tem desempenhado papel instrumental na promoção da diversificação das exportações de bens não tradicionais e de crescimento econômico, através do fornecimento de capacidades tecnológicas, organizacional, marketing e assistência à agroindústria incipiente.

A Argentina, por sua vez, apresentou resultados não significativos para a maioria das cestas em relação às variáveis explicativas. O país foi o que mais sofreu com as crises cambial e financeira na década de 90 e início da década de 2000, refletindo em elevada volatilidade nas variáveis socioeconômicas.

\section{Conclusão}

Com base na acentuada dispersão entre a produtividade implícita dos produtos do agronegócio, pode-se afirmar que existe uma distância considerável entre se especializar em "Peles de cabra e cabrito" e de "Papel gomado ou adesivo em tiras ou rolos". Essa diferença vai além do valor agregado entre os dois produtos e pode representar, implicitamente, especialização em distinto poder de encadeamento entre setores e de diversificação das exportações, incorporando maior ou menor qualidade na produção, acúmulo de competências científicas e biotecnológicas, de habilidades internas pessoais e de logística etc.

O grau de sofisticação das exportações dos produtos do agronegócio na sub-região ficou abaixo da média mundial, pois, de modo geral, os produtos do agronegócio mais exportados pelos países (maior peso na pauta de exportação) da sub-região correspondem àqueles exportados pelos países de menor nível de renda per capita. De modo geral, o Cone Sul, mais recentemente, ampliou sua especialização em produtos ligados à especialização ricardiana, isto é, vinculadas às vantagens naturais de seus recursos disponíveis. A exceção é o Chile, que vem buscando maior diversificação e sofisticação de suas exportações, especializando-se em produtos associados ao maior nível de renda (maior produtividade implícita).

Para as décadas estudadas (90 e 2000), a renda percapita dos paíseslatino-americanosecaribenhos move-se no mesmo sentido da sofisticação de suas cestas de exportações dos produtos do agronegócio, com maior grau de associação na segunda década. Países posicionados em grau mais elevado na sofisticação de sua cesta de exportação de produtos do agronegócio têm maior nível de renda. Essa é uma relação importante, dado que foram considerados no estudo apenas os produtos do agronegócio para a composição da cesta de sofisticação e, ainda, existe diversidade acentuada quanto à participação na pauta de exportação desses produtos entre os países.

Apesar das limitações dos dados e da dificuldade para obtenção de tendência na primeira década, observa-se que o efeito multiplicador da sofisticação da cesta de exportação, para a maioria dos casos, associa-se positivamente às variáveis renda agrícola, produto e ocupação, porém, em menor grau para a última. Ainda observa-se que esse efeito varia em função da evolução do grau de contribuição das categorias de produtos, se de baixa, média ou alta produtividade implícita. Assim, em países que exportam produtos do agronegócio mais sofisticados, por possuírem maior apreensão de capacidades e maior integração entre a agricultura e os demais setores, o impacto positivo sobre a economia é maior.

Contudo, pode-se afirmar que a especialização em produtos do agronegócio pode representar um nível maior de desenvolvimento para a maioria dos países. Aprofundar na sofisticação das cestas de produtos do agronegócio importa como estratégia de política para a convergência de renda em direção aos países mais ricos.

Nesta perspectiva, dada a importância dos produtos do agronegócio para a sub-região e a ampla margem para a exploração das suas potencialidades e capacidades a serem 
desenvolvidas, os governos, através de "políticas ativas", têm papel importante e potencialmente positivo a desempenhar na condução da estrutura produtiva e exportadora dos países, ampliando e socializando os benefícios de crescimento induzido pelo comércio exterior.

\section{Referências bibliográficas}

BRAGANÇA, A. A.; LEMOS, B. e AMARAL, P. V. M. Estrutura produtiva e crescimento econômico regional. In: ENCONTRO NACIONAL DE ECONOMIA DA ANPEC, 37., 2009, Foz do Iguaçu. Anais... Foz do Iguaçu: ANPEC, 2009. Disponível em: <www.anpec. org.br/encontro_2009.htm > . Acesso em: 22 maio 2010.

CHANG, H-J. Kicking away the ladder: development strategy in historical perspective. London: Anthem Press, 2002. 256 p.

GONÇALVES, R. et al. A nova economia internacional: uma perspectiva brasileira. Rio de Janeiro: Campus, 1998. $392 \mathrm{p}$.

- Exportação de bovino vivo: problemas, riscos e soluções. Rio de Janeiro: IE, nov., 2008. 51 p. (Texto para Discussão) Disponível em: <www.ie.ufrj.br/hpp/ mostraArtigos.php? idprof $=77 \&$ cat $=1>$. Acesso em: 14 jun. 2011.

FERRANTI, D. et al. Beyond the city: the rural contribution to development. Washington: World Bank Latin American and Caribbean, 2005. (Studies series). Disponível em: <http://web.worldbank.org>. Acesso em: 18 maio 2010.

HAUSMANN, R. e HIDALGO, C. A. Country diversification, product ubiquity, and economic divergence. Harvard: Harvard University, 2010. 43 p. (CID working paper, 201). Disponível em: <http://www.hks.harvard. edu/centers/cid/publications /faculty-working-papers/ cid-orking-paper-no.-201 > . Acesso em: 13 jul. 2011.

HAUSMANN, R.; HWANG, J. e RODRIK, D. What you export matters. Journal of Economic Growth, Cambridge, v. 12, n. 1, p. 1-25, 2005. Disponível em: < http://www. nber.org/papers/w11905>. Acesso em: 05 abr. 2010

HAUSMANN, R. e KLINGER, B. Structural transformation and patterns of comparative advantage in the product space. Harvard: Harvard University, 2006. 38 p. (CID working paper, 128). Disponível em: <http:// www.cid.harvard.edu/cidwp/128.htm>. Acesso em: 17 jun. 2010.
HIDALGO, C. A. et al. The product space conditions the development of nations. Science, Washington, v. 317 , n. 27, p. 482-487, 2007. Disponível em: <www. sciencemag.org >. Acesso em: 13 mar. 2011.

HIRSCHMAN, A. O. Grandeza e decadência da economia do desenvolvimento. In: HIRSCHMAN, A. O. A economia como ciência moral e política. São Paulo: Brasiliense, 1981.

KALDOR, N. Un modelo de distribución. In: SEN, Amartya (Org.). Economía del crecimiento: selección de Amartya Sen. Ciudad de México: Fondo de Cultura Econômica, 1989.

LIAPIS, P.Changing patterns of tradein processedagricultural products. Paris: OECD, 2011. 22 p. (Agriculture and fisheries working papers, 47). Disponível em: $<$ http:// dx.doi.org/10.1787/5kgc3mq19s6d-en>. Acesso em: 15 jul. 2011.

MYRDAL, G. Teoria econômica e regiōes subdesenvolvidas. Rio de Janeiro: Saga, 1968.

NORTH, D. C. Agriculture in regional economic growth. Journal of Farm Economics, Oxford, v. 41, n. 5, p. 943-951, 1959.

NURKSE, R. Problemas da formação de capital em países subdesenvolvidos. Rio de Janeiro: Civilização Brasileira, 1957.

PALMA, G. Gansos voadores e patos vulneráveis: a diferença da liderança do Japão e dos Estados Unidos, no desenvolvimento do Sudeste Asiático e da América Latina. In: FIORI, José Luís (Org.). O poder americano. Petrópolis: Vozes, 2004.

.Quatrofontesde"desindustrialização" eumnovo conceito de "doença holandesa". In: CONFERÊNCIA DE INDUSTRIALIZAÇÃO, DESINDUSTRIALIZAÇÃO E DESENVOLVIMENTO, 2005, São Paulo. São Paulo: FIESP; IEDI, 2005. Disponível em: <www.fiesp.com. br/download/ publicacoes.../jose_gabriel_palma.pdf $>$. Acesso em: 13 maio 2010.

RODRÍGUEZ, O. Teoria do subdesenvolvimento da CEPAL. Rio de Janeiro: Forense-Universitária, 1981.

RODRIK, D. Growth Strategies. In: AGHION, P. e DURLAUF, S. (Ed.). Handbook of economic growth. Amsterdam: Elsevier North-Holland, 2005.

THIRLWALL A. P. A natureza do crescimento econômico: um referencial alternativo para compreender $\mathrm{o}$ desempenho das nações. Brasília: IPEA, 2005.

TRIVIÑOS, A.N.S. Introdução à pesquisa em ciências sociais: a pesquisa qualitativa em educação. São Paulo, Atlas, 1987. 
UNCTAD. UNCTAD online statistics. New York: United Nations, 2011. Disponível em: <http://www.unctad. org/Templates/Page.asp?intItemID $=1584 \&$ lang $=1>$. Acesso em: 25 abr. 2011.

UNITED NATIONS ORGANIZATION. UNcontrade. United Nations Statistics, Division International Merchandise Trade Statistics (IMTS), 2011. Disponível em: <http://comtrade.un.org/> Acesso em: 30 mar. 2011.

WILKINSON, J. Sociologia econômica, a teoria das convenções e o funcionamento dos mercados: inputs para analisar os micro e pequenos empreendimentos agroindustriais no Brasil. Ensaios FEE, Porto Alegre, v. 23 , n. 2, p. $805-824,2002$ a. 
